\title{
Tannic acid alleviates lipopolysaccharide-induced H9C2 cell apoptosis by suppressing reactive oxygen species-mediated endoplasmic reticulum stress
}

\author{
YAN-PING YANG ${ }^{1}$, JIE-QIONG ZHAO ${ }^{1}$, HAI-BO GAO ${ }^{1}$, JIN-JING LI ${ }^{1}$, \\ XIAO-LI LI ${ }^{1}$, XIAO-LIN NIU ${ }^{1}$, YONG-HONG LEI ${ }^{2}$ and XUE LI ${ }^{1}$ \\ ${ }^{1}$ Department of Cardiology, Tangdu Hospital, Fourth Military Medical University, Xi'an, Shaanxi 710038; \\ ${ }^{2}$ Department of Plastic Surgery, General Hospital of Chinese PLA, Beijing 100853, P.R. China
}

Received October 12, 2020; Accepted April 30, 2021

DOI: $10.3892 / \mathrm{mmr} .2021 .12174$

\begin{abstract}
Sepsis-induced myocardial dysfunction is one of the features of multiple organ dysfunction in sepsis, which is associated with extremely high mortality and is characterized by impaired myocardial compliance. To date, there are few effective treatment options available to cure sepsis. Tannic acid (TA) is reportedly protective during sepsis; however, the underlying mechanisms by which TA protects against septic heart injury remain elusive. The present study investigated the potential effects and underlying mechanisms of TA in alleviating lipopolysaccharide (LPS)-induced H9C2 cardiomyocyte cell apoptosis. $\mathrm{H} 9 \mathrm{C} 2$ cells were treated with LPS $(15 \mu \mathrm{g} / \mathrm{ml})$, TA $(10 \mu \mathrm{M})$ and TA + LPS; control cells were treated with medium only. Apoptosis was measured using flow cytometry, reverse transcription-quantitative PCR (RT-qPCR) and western blot analysis. Additionally, the levels of cellular reactive oxygen species (ROS), malondialdehyde and nicotinamide adenine dinucleotide phosphate were
\end{abstract}

Correspondence to: Professor Xue Li, Department of Cardiology, Tangdu Hospital, Fourth Military Medical University, 1 Xinsi Road, Xi'an, Shaanxi 710038, P.R. China

E-mail: cliresearch@163.com

Professor Yong-Hong Lei, Department of Plastic Surgery, General Hospital of Chinese PLA, 28 Fuxing Street, Beijing 100853, P.R. China

E-mail: lyhhlx@126.com

Abbreviations: TA, tannic acid; LPS, lipopolysaccharide; SIMD, sepsis-induced myocardial dysfunction; ROS, reactive oxygen species; ERS, endoplasmic reticulum stress; UPR, unfolded protein response; IRE1, inositol-requiring enzyme 1; ATF6, activating transcription factor 6; PERK, protein kinase-like endoplasmic reticulum kinase; $\mathrm{Xbp1s}$, spliced $\mathrm{X}$ box-binding protein 1; Cyt $\mathrm{c}$, cytochrome $c$; CHOP, C/EBP-homologous protein; JNK, c-Jun $\mathrm{N}$-terminal kinase; NAC, N-acetylcysteine; MDA, malondialdehyde; NADPH, nicotinamide adenine dinucleotide phosphate

Key words: TA, LPS, ROS, ERS, apoptosis evaluated. Western blotting and RT-qPCR were also employed to detect the expression levels of endoplasmic reticulum (ER) stress-associated functional proteins. The present findings demonstrated that TA reduced the degree of LPS-induced H9C2 cell injury, including inhibition of ROS production and ER stress (ERS)-associated apoptosis. ERS-associated functional proteins, including activating transcription factor 6 , protein kinase-like ER kinase, inositol-requiring enzyme 1, spliced $\mathrm{X}$ box-binding protein 1 and C/EBP-homologous protein were suppressed in response to TA treatment. Furthermore, the expression levels of ERS-associated apoptotic proteins, including c-Jun $\mathrm{N}$-terminal kinase, Bax, cytochrome $c$, caspase-3, caspase-12 and caspase- 9 were reduced following treatment with TA. Additionally, the protective effects of TA on LPS-induced H9C2 cells were partially inhibited following treatment with the ROS inhibitor $\mathrm{N}$-acetylcysteine, which demonstrated that ROS mediated ERS-associated apoptosis and TA was able to decrease ROS-mediated ERS-associated apoptosis. Collectively, the present findings demonstrated that the protective effects of TA against LPS-induced $\mathrm{H} 9 \mathrm{C} 2$ cell apoptosis may be associated with the amelioration of ROS-mediated ERS. These findings may assist the development of potential novel therapeutic methods to inhibit the progression of myocardial cell injury.

\section{Introduction}

Sepsis is a life-threatening multiple organ dysfunction syndrome (MODS), which is characterized by a disordered immune, endocrine and metabolic response to infection $(1,2)$. Severe sepsis may result in significant morbidity and mortality $(3,4)$. Myocardial dysfunctions are common among patients with severe sepsis and cardiac dysfunction is a well-recognized feature of MODS $(5,6)$. Sepsis-induced myocardial dysfunction (SIMD) has been identified as a sepsis-associated acute syndrome of cardiac dysfunction. Numerous factors, such as lipopolysaccharide (LPS), tumor necrosis factor- $\alpha$ and IL-1, are associated with $\operatorname{SIMD}(7,8)$. In addition, several mechanisms have been proposed to explain the pathophysiology of SIMD, including excessive generation of inflammatory cytokines, reactive oxygen species (ROS) or 
nitrogen radicals, as well as transcriptional and compromised metabolic changes (9-12). Despite extensive studies, to the best of our knowledge, the relevant pathogenesis of SIMD has not yet been clearly defined $(11,12)$.

LPS is a component of the outer membrane of Gram-negative bacteria and has been regarded as the principal cause of cardiac dysfunction in sepsis (13). LPS associates with its receptor, Toll-like receptor 4 , to stimulate the production of inflammatory cytokines and simultaneously generate abundant ROS, which may directly disturb cardiac function $(11,12)$. ROS are by-products of normal cellular oxidative processes and are generated in response to external stimuli, such as inflammatory cytokines, including LPS, chemotherapeutic drugs and ionizing radiation $(14,15)$. Excessive ROS are considered to be a marker of oxidative stress and can cause cell apoptosis (16). Enhancing the cellular antioxidant capacity or ROS-scavenging activity may act to ameliorate the imbalance in a variety of pathologies and disease models $(12,14)$. Excessive ROS production can trigger endoplasmic reticulum (ER) stress (ERS), which is called ROS-mediated ERS (17). ERS is one of the mechanisms contributing to ROS-mediated cell apoptosis (18), and ERS-associated cardiomyocyte apoptosis has been reported to be a major contributor to myocardial injury (19). The ER is responsible for the folding of secretory and membrane proteins. In mammals, the ERS response is mediated by three known transmembrane sensor proteins in the ER, namely inositol-requiring enzyme 1 (IRE1), activating transcription factor 6 (ATF6) and protein kinase-like ER kinase (PERK). Numerous intracellular and extracellular stimuli, such as nutrient deficiency, viral infection and abnormal protein expression arising from gene mutations, have been shown to cause the accumulation of unfolded and misfolded proteins, resulting in the dissociation of glucose-regulated protein 78 from the three ER transmembrane protein sensors, PERK, ATF6 and IRE1, and subsequently triggering the unfolded protein response (UPR) (20). Large or prolonged stimuli activate ERS-related C/EBP-homologous protein (CHOP), caspase 12 and/or c-Jun N-terminal kinase (JNK)-dependent apoptotic signaling pathways $(21,22)$. Attenuation of ERS with pharmacological or gene therapy strategies has been successful in reducing pathological features in various experimental models of inflammatory diseases, including sepsis $(23,24)$. Therefore, SIMD may be alleviated by the regulation of ROS and ERS. There is an urgent need for innovative therapeutic options for the treatment of SIMD, in order to decrease mortality from sepsis.

Tannic acid (TA; chemical structure, $\mathrm{C}_{76} \mathrm{H}_{52} \mathrm{O}_{46}$ ) is a specific type of tannin, which is a water-soluble polyphenol, and is a mixture of five galloyl esters and one glucose (25). Previous studies have indicated that TA possesses anticarcinogenic, antioxidant, antimutagenic, anti-inflammatory, antifibrotic and cardioprotective effects (26-30). To date, to the best of our knowledge, there are no published scientific reports on the effects of TA on LPS-induced myocardial injury or related ailments. Whether ERS regulates the inhibitory effects of TA during LPS-induced myocardial dysfunction remains unknown. Additionally, the specific mechanism by which TA alleviates myocardial dysfunction urgently needs to be investigated. Therefore, the present study aimed to identify the role of TA in LPS-induced cardiomyocyte injury and to elucidate the underlying mechanisms using H9C2 cells.

\section{Materials and methods}

Materials. TA (cat. no. T0801) was purchased from Shanghai Topscience Co., Ltd. N-Acetylcysteine (NAC; cat. no. HY-B0215) was purchased from MedChemExpress. LPS (from Escherichia coli O55:B5) was purchased from Sigma-Aldrich; Merck KGaA, and the rat heart myoblast cell line H9C2(2-1) (cat. no. GNR 5) was obtained from The Cell Bank of Type Culture Collection of The Chinese Academy of Sciences. High-glucose DMEM (cat. no. 12800017) and fetal bovine serum (FBS; cat. no. 10270106) were purchased from Gibco; Thermo Fisher Scientific, Inc. Phosphate-buffered saline (PBS; cat. no. SH30256.01) and trypsin (cat. no. SH30042.01) were purchased from HyClone; Cytiva. Pierce ${ }^{\mathrm{TM}}$ BCA Protein Assay kit (cat. no. 23227) was obtained from Thermo Fisher Scientific, Inc. Cellular ROS Detection Assay kit was purchased from Nanjing Jiancheng Bioengineering Institute. Cell Counting Kit-8 (CCK-8) assay was purchased from Seven Seas Futai. Culture dishes (cat. nos. 430166 and 430167) were purchased from Corning, Inc.

Antibodies. The primary antibody directed against $\beta$-actin (cat. no. ab8227) was purchased from Abcam. Primary antibodies against cleaved caspase-3 (cat. no. BF0711), cleaved caspase-9 (cat. no. AF5240), Bax (cat. no. AF0120), Bcl-2 (cat. no. AF6139), ATF6 (cat. no. DF6009), CHOP (cat. no. F6025), phosphorylated (p)-PERK (cat. no. DF7576), PERK (cat. no. AF4799), p-IRE1 (cat. no. AF7150), IRE1 (cat.no. DF7709), p-JNK (cat. no. AF3318) and JNK (cat. no. AF6318) were obtained from Affinity Biosciences. HRP-conjugated secondary antibodies (cat nos. ab6721 and ab6885) were purchased from Abcam.

Cell culture and treatment. The H9C2 cells were cultured in high-glucose DMEM supplemented with $10 \%$ (v/v) FBS, $1.5 \mathrm{~g} / 1 \mathrm{NaHCO} 3$ and $1 \%$ penicillin-streptomycin (Gibco; Thermo Fisher Scientific, Inc.) at $37^{\circ} \mathrm{C}$ in a humidified atmosphere containing $5 \% \mathrm{CO}_{2}$ and were maintained in a logarithmic growth phase for all experiments. According to a previous study (31), H9C2 cells were treated with LPS $(15 \mu \mathrm{g} / \mathrm{ml})$ for $12 \mathrm{~h}$, and with different concentrations of TA $(0,5,10,20,30$ and $40 \mu \mathrm{M})$ for 12 or $24 \mathrm{~h}$. In addition, H9C2 cells were pretreated with $10 \mu \mathrm{M}$ TA $2 \mathrm{~h}$ prior to treatment with LPS $(15 \mu \mathrm{g} / \mathrm{ml})$ for $12 \mathrm{~h}$. For ROS inhibition experiments, the inhibitor NAC ( $2 \mathrm{mM})$ was added for $1 \mathrm{~h}$ prior to exposure to $10 \mu \mathrm{M}$ TA. H9C2 cells were treated with TA $(10 \mu \mathrm{M})$ and NAC ( $2 \mathrm{mM})$ alone for $12 \mathrm{~h}$. All treatments were performed at $37^{\circ} \mathrm{C}$ in a humidified atmosphere containing $5 \% \mathrm{CO}_{2}$.

CCK-8 assay. The H9C2 cells were seeded in a 96-well plate at a density of 5,000 cells/well, and treated as follows: Fresh culture medium alone (control group); fresh culture medium with different concentrations $(0-50 \mu \mathrm{M})$ of TA and/or fresh culture medium with $15 \mu \mathrm{g} / \mathrm{ml}$ LPS for the indicated times. All treatments were performed at $37^{\circ} \mathrm{C}$ in a humidified atmosphere containing $5 \% \mathrm{CO}_{2}$. Cell viability was assessed using the CCK-8 assay, according to the manufacturer's instructions. Briefly, after treatment, CCK-8 solution (10 $\mu \mathrm{l})$ was added to each well and the cultures were incubated at $37^{\circ} \mathrm{C}$ in humidified atmosphere containing $95 \%$ air and $5 \%$ 
$\mathrm{CO}_{2}$ for $1 \mathrm{~h}$. Absorbance was measured at $450 \mathrm{~nm}$ using a microplate reader (Bio-Rad Laboratories, Inc.). Values were expressed as the percentage of viable cells as follows: Relative viability $(\%)=[\mathrm{OD} 450$ (treated) - OD450 (blank)]/[OD450 (control) - OD450 (blank)] x 100. To exclude cell toxicity, one concentration of TA $(10 \mu \mathrm{M})$ was used in subsequent experiments.

Measurement of cellular ROS levels. The Cellular ROS Detection Assay kit contains the fluorogenic dye, 2,7-dichlorofluorescin-diacetate (DCFDA), which measures ROS activity within the cell. After diffusion into the cell, DCFDA is deacetylated by cellular esterases to a non-fluorescent compound, which is later oxidized by ROS into 2',7'-dichlorofluorescein (DCF). DCF is a highly fluorescent compound, which can be detected by fluorescence spectroscopy with excitation/emission at $485 / 535 \mathrm{~nm}$. In the present study, the $\mathrm{H} 9 \mathrm{C} 2$ cells (70-80\% confluent) were incubated with DCFDA $(10 \mu \mathrm{M})$ for $30 \mathrm{~min}$ at $37^{\circ} \mathrm{C}$ in the dark. The cells were subsequently washed twice with PBS and observed under a confocal laser scanning microscope (Leica Microsystems, Inc.), and the images were captured. The mean fluorescence intensity of DCF was analyzed using ImageJ (version 1.46) software (National Institutes of Health).

The H9C2cells werealsocollected toassessmalondialdehyde (MDA) and nicotinamide adenine dinucleotide phosphate (NADPH) levels; $0.1 \mathrm{ml}$ lysate or homogenate extracted from $10^{6}$ cells was used. After homogenization or pyrolysis, the supernatant was centrifuged at $6,000 \times \mathrm{g}$ for $10 \mathrm{~min}$ at $4^{\circ} \mathrm{C}$ and the supernatant was then stored at $-80^{\circ} \mathrm{C}$. Subsequently, MDA (cat. no. S0131S) and NADPH (cat. no. ST360) levels were detected according to the instructions of commercial kits (Beyotime Institute of Biotechnology).

Flow cytometric analysis of apoptosis. Annexin V-FITC was used to measure the apoptosis of $\mathrm{H} 9 \mathrm{C} 2$ cells as described previously (32). The necrotic cells were counterstained with propidium iodide (PI). Briefly, cells were plated in $60-\mathrm{mm}$ dishes and exposed to different treatments once they reached $80-85 \%$ confluence. Detached and adherent cells were collected, washed twice with cold PBS, and then resuspended in $1 \mathrm{X}$ binding buffer [BD Pharmingen ${ }^{\mathrm{TM}}$ FITC Annexin V Apoptosis Detection kit I (cat. no.556547)] at a concentration of $1 \times 10^{6}$ cells $/ \mathrm{ml}$. The resuspended solution containing $1 \times 10^{5}$ cells $(100 \mu \mathrm{l})$ was transferred to a 5 -ml culture tube, to which $5 \mu \mathrm{l}$ Annexin V-FITC and $5 \mu \mathrm{l}$ PI were added, and gently vortexed prior to 15 -min incubation at $25^{\circ} \mathrm{C}$ in the dark. Subsequently, $1 \mathrm{X}$ binding buffer $(400 \mu \mathrm{l})$ was added to each tube at room temperature and the percentages of early + late apoptotic cells were analyzed by flow cytometry (Beckman Coulter; COULTER-XL.MCL) within $1 \mathrm{~h}$ and EXPO32 (Applied Cytometry Systems) was used for analysis.

Reverse transcription-quantitative PCR (RT-qPCR). RT-qPCR analysis was performed as described previously (33). The primer sequences are described in Table I. Briefly, total RNA was extracted using TRIzol ${ }^{\circledR}$ (cat. no. 15596026; Invitrogen; Thermo Fisher Scientific, Inc.) and DNase was used to remove internal DNA contamination. Random primers (cat. no. K1622; Thermo Fisher Scientific, Inc.) were used in RT reactions to
Table I. Primers used for reverse transcription-quantitative PCR analyses in the present study.

\begin{tabular}{ll} 
Rat target genes & \multicolumn{1}{c}{ Primer sequences } \\
\hline Gapdh & F: 5'-ACAGCAACAGGGTGGTGGAC-3' \\
& R: 5'-TTTGAGGGTGCAGCGAACTT-3' \\
Atf6 & F: 5'-GAACTTCGAGGCTGGGTTCA-3' \\
& R: 5'-AACTTCCAGGCGAAGCGTAA-3' \\
Xbp1s & F: 5'-GTGTCTAAAGCCACCCACCA-3' \\
& R: 5'-ACCTTTGAAGACCTCAGACAGC-3' \\
Chop & F: 5'-GCTCAAGCAGGAAATCGAGC-3' \\
& R: 5'-CAAGCCCCTCTCCTTTGGTC-3' \\
Bax & F: 5'-TGGGATGGCCTCCTTTCCTA-3' \\
& R: 5'-TTCCCCGTTCCCCATTCATC-3' \\
Cyt c & F: 5'-ATGCTGCCTTTCACCACTGA-3' \\
& R: 5'-GTACCACTCCCAATCAGGCA-3' \\
Caspase-3 & F: 5'-ACTGGAATGTCAGCTCGCAA-3' \\
& R: 5'-TTTTCAGGTCCACAGGTCCG-3' \\
Caspase-12 & F: 5'-GTTTGGCCAAGGACATGCTG-3' \\
& R: 5'-GCTGTTTGTCGGAATTGGCA-3' \\
Perk & F: 5'-CTTTCGGTGCTCCAAGGCTC-3' \\
Ire1 & R: 5'-CGTATCCGATGTGGGAGCAA-3' \\
& F: 5'-ATGGGTGGCGTTCATCATCA-3' \\
& R: 5'-AGGGTCCTGGGTAAGGTCTC-3'
\end{tabular}

Atf6, activating transcription factor 6 ; Xbp1s, spliced $\mathrm{X}$ box-binding protein 1; Chop, C/EBP-homologous protein; Cyt c, cytochrome $c$; Perk, protein kinase-like endoplasmic reticulum kinase; Ire1, inositol-requiring enzyme 1; F, forward; R, reverse.

obtain first-strand cDNA according to the manufacturer's instructions, and SYBR-Green qPCR Master Mix (cat. no. FP202; Tiangen Biotech Co., Ltd.) was used to amplify the target fragments. Gapdh cDNA amplification was used as an internal control. The general qPCR procedure included an initial denaturing step at $95^{\circ} \mathrm{C}$ for $15 \mathrm{~min}$, followed by 37 cycles of denaturing at $95^{\circ} \mathrm{C}$ for $10 \mathrm{sec}$, annealing at $57^{\circ} \mathrm{C}$ for $30 \mathrm{sec}$ and extension at $72^{\circ} \mathrm{C}$ for $30 \mathrm{sec}$, with a plate read at $95^{\circ} \mathrm{C}$ for 5 sec. GAPDH was used as a reference gene with the DCT method to quantify the results (33). Each experimental group was assessed in triplicate. IBM SPSS (version 19) software was used to analyze differences in expression.

Western blotting. Western blotting was performed as described previously (34). Briefly, cells werelysed inlysis buffercontaining $50 \mathrm{mM}$ Tris- $\mathrm{HCl}$ (pH 7.4), $150 \mathrm{mM} \mathrm{NaCl}, 1 \mathrm{mM}$ EDTA, $0.25 \%$ sodium deoxycholate and 1\% NP-40, with a protease inhibitor cocktail and phosphatase inhibitor cocktail; the insoluble components were removed by centrifugation at $12,000 \mathrm{x} \mathrm{g}$ for $15 \mathrm{~min}$ at $4^{\circ} \mathrm{C}$. Subsequently, protein concentrations were measured using the BCA method. After denaturation, the total proteins $(25 \mu \mathrm{g})$ were separated by SDS-PAGE on $10 \%$ gels and transferred onto 0.2 - or $0.45-\mu \mathrm{m}$ polyvinylidene fluoride membranes. After blocking with $5 \%(\mathrm{w} / \mathrm{v})$ non-fat milk for $2 \mathrm{~h}$ at room temperature, the membranes were incubated with primary antibodies diluted in blocking buffer $(1: 1,000)$ overnight at $4^{\circ} \mathrm{C}$. The membranes were subsequently washed 
A

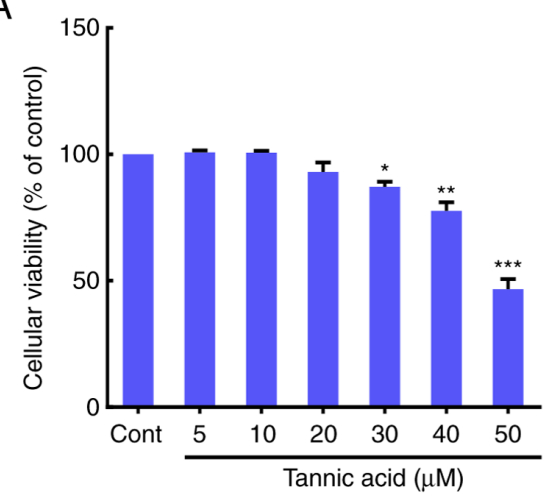

$\mathrm{B}$

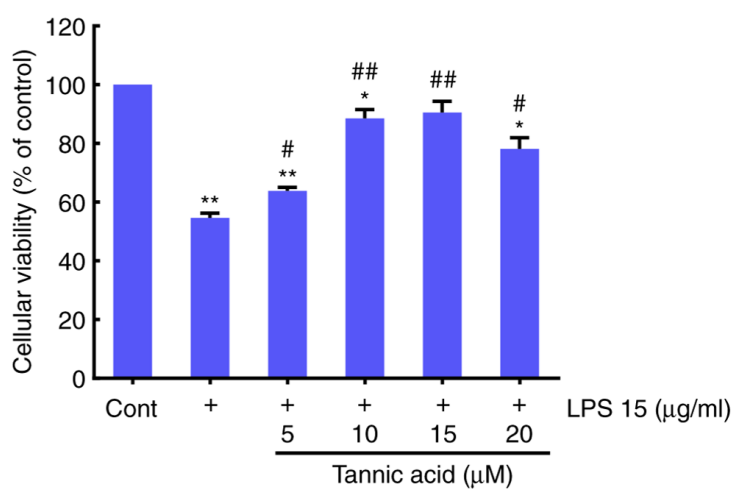

Figure 1. Effect of TA on H9C2 cell viability. Cell viability was determined using the Cell Counting Kit- 8 assay. (A) Viability of H9C2 cells treated with various concentrations of TA $(0,5,10,20,30,40$ and $50 \mu \mathrm{M})$ for $24 \mathrm{~h}$. (B) Viability of H9C2 cells pretreated with a series of concentrations of TA $(0,5,10,15$ and $20 \mu \mathrm{M})$ for $2 \mathrm{~h}$, and then treated with $15 \mu \mathrm{g} / \mathrm{ml}$ LPS for a further $24 \mathrm{~h}$. Data are presented as the mean \pm standard error of the mean $(\mathrm{n}=3)$. ${ }^{*} \mathrm{P}<0.05,{ }^{* *} \mathrm{P}<0.01$ and ${ }^{* * * *} \mathrm{P}<0.001$ vs. Cont group; ${ }^{\#} \mathrm{P}<0.05$ and ${ }^{\# \#} \mathrm{P}<0.01$ vs. LPS group. TA, tannic acid; LPS, lipopolysaccharide; Cont, control.

three times with $1 \mathrm{X}$ TBS-0.1\% Tween-20 (TBST), and further incubated with HRP-conjugated secondary antibodies $(1: 5,000)$ for $2 \mathrm{~h}$ at room temperature. After subsequent washes of the membrane, three times with $1 \mathrm{X}$ TBST, antibody detection was performed using the Immobilon Western Chemiluminescent HRP Substrate (cat. no. WBKLS0500; Merck KGaA) and a ChemiDoc $^{\mathrm{TM}}$ XRS+ system (Bio-Rad Laboratories, Inc.). ImageJ (version 1.46; National Institutes of Health) was used to compare the gray values of the target bands; GAPDH served as an internal control.

Statistical analysis. Data are presented as the mean \pm standard error of the mean from at least three independent experiments. GraphPad Prism 8.0.2 (GraphPad Software Inc.) was used for statistical analysis. Statistical significance was determined by one-way ANOVA with Bonferroni correction for multiple comparisons. $\mathrm{P}<0.05$ was considered to indicate a statistically significant difference.

\section{Results}

Effect of TA on LPS-induced viability of H9C2 cells. Prior to investigating whether TA protected H9C2 cells from LPS-induced cell injury, the cytotoxicity of the extract was determined. Cell viability was assessed using the CCK-8 assay and the results revealed that cell viability was slightly increased in response to TA concentrations $\leq 10 \mu \mathrm{M}$; however, these increases were not statistically significant when compared with the control group (Fig. 1A). Following treatment of H9C2 cells with TA concentrations $\geq 30 \mu \mathrm{M}$, cell viability was significantly decreased; therefore, to exclude cell toxicity, 5, 10 and $20 \mu \mathrm{M}$ concentrations were selected for the subsequent experiment. To examine the effects of TA on LPS-induced cell injury, the viability of H9C2 cells pretreated with $0,5,10,15$ and $20 \mu \mathrm{M}$ TA and then treated with $15 \mu \mathrm{g} / \mathrm{ml}$ LPS was determined. As shown in Fig. 1B, LPS treatment significantly diminished cell viability to $50.65 \pm 0.5 \%$ compared with the control group. Notably, pretreatment with TA $(5,10$ and $15 \mu \mathrm{M}$ ) prior to LPS treatment significantly improved cell viability compared with the LPS-treated group to $68.3 \pm 0.8$, $84.6 \pm 2.1$ and $90.6 \pm 3.3 \%$, respectively. Cell viability was slightly decreased in response to $20 \mu \mathrm{M}$ TA compared with $15 \mu \mathrm{M}$ TA. These findings demonstrated that pretreatment with TA dose-dependently increased cell viability, which was diminished by LPS treatment, thus suggesting that TA may be capable of protecting H9C2 cells from LPS-induced cell injury.

TA alleviates the LPS-induced apoptosis of H9C2 cells. To further evaluate the effect of TA on LPS-induced apoptosis, H9C2 cells were treated with LPS or a combination of TA and LPS. Cell apoptosis was measured by flow cytometry, and the expression levels of apoptosis-associated proteins in $\mathrm{H} 9 \mathrm{C} 2$ cells were measured by western blotting. As presented in Fig. 2A and B, the percentage of apoptotic cells was significantly increased after LPS treatment compared with that in the control group. Conversely, pretreatment with TA significantly decreased the percentage of apoptotic cells induced by LPS treatment. Consistent with the results of flow cytometry, LPS increased the protein expression levels of apoptotic markers, Bax/Bcl2, cleaved caspase-3 and cleaved caspase-9, compared with those in the control group. However, pretreatment with TA decreased the expression levels of these markers compared with treatment with LPS alone (Fig. 2C and D). Notably, the detected levels of all markers in the TA-only group were comparable to those detected in the control (medium) group. These results suggested that TA alleviated LPS-induced H9C2 cell apoptosis.

TA attenuates ROS generation in LPS-induced H9C2 cells. The level of ROS is a crucial index of oxidative stress. To further evaluate the effects of TA on LPS-induced oxidative stress, the levels of intracellular ROS were monitored by detecting changes in DCF fluorescence by laser confocal microscopy. As shown in Fig. 3A and B, LPS treatment significantly elevated ROS generation compared with that in the control group; however, the LPS-mediated increase in DCF fluorescence was significantly decreased with TA pretreatment. Notably, the ROS levels detected in the TA-only group were comparable to those in the control group treated with medium only, demonstrating the minimum cell toxicity of the chosen TA dose. 
A
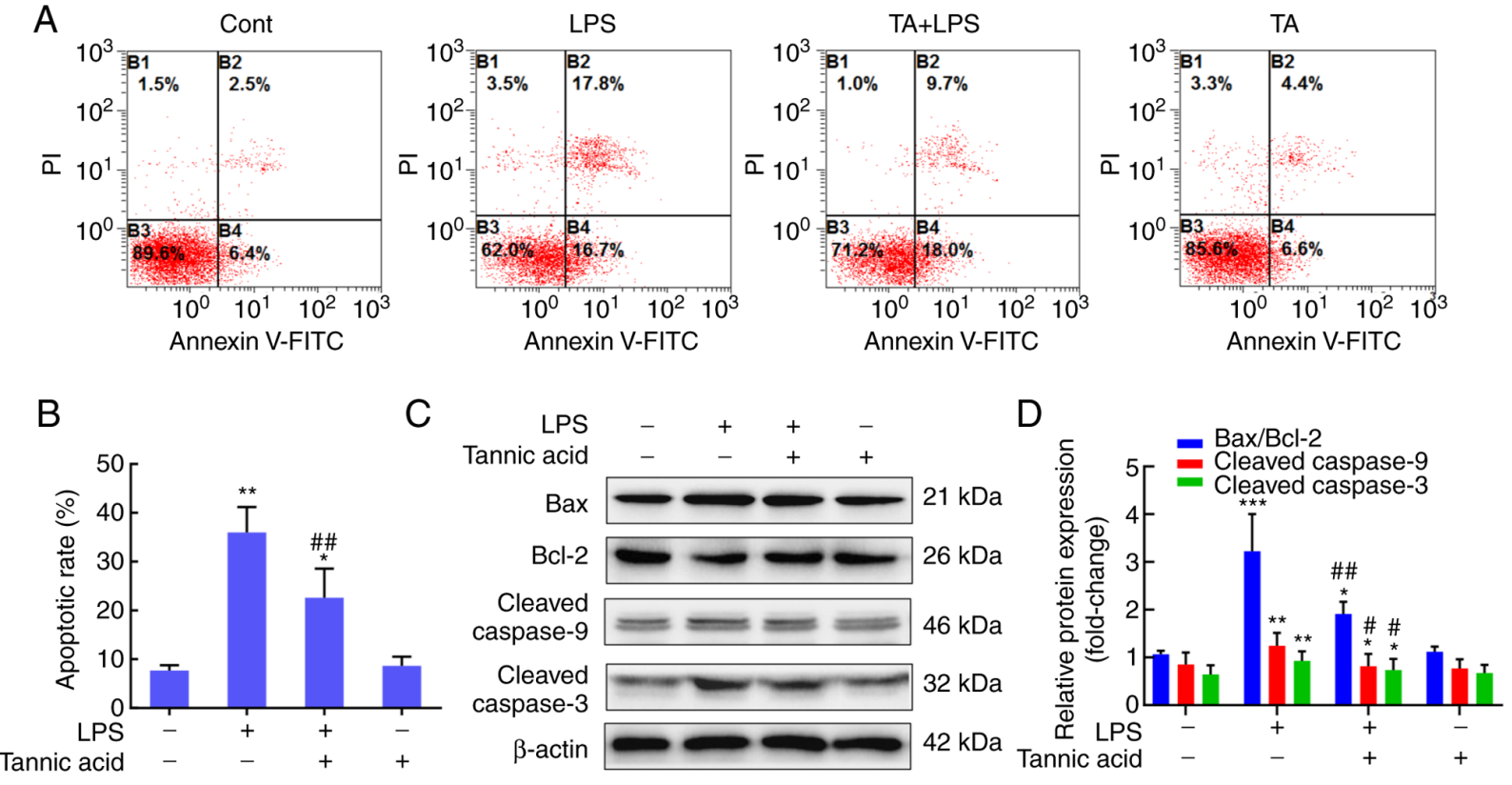

Figure 2. TA alleviates the LPS-induced apoptosis of H9C2 cells. (A) Flow cytometry was used to determine cell apoptotic rate using Annexin V-FITC/PI staining. Apoptotic cells included Annexin V+/PI- and Annexin V+/PI+ cells. (B) Quantitative analysis of the apoptotic rate of cells treated with LPS, TA and TA + LPS. (C) Protein expression levels of Bax, Bcl-2, cleaved caspase-9, cleaved caspase-3 and $\beta$-actin in H9C 2 cells treated with LPS, TA or TA + LPS were determined by western blot analysis. (D) Semi-quantification of the protein expression levels of Bax/Bcl-2, cleaved caspase- 9 and cleaved caspase-3 in the LPS, TA and TA + LPS groups. Data are presented as the mean \pm standard error of the mean $(\mathrm{n}=3)$. ${ }^{*} \mathrm{P}<0.05,{ }^{* *} \mathrm{P}<0.01$ and ${ }^{* * *} \mathrm{P}<0.001$ vs. Cont group; ${ }^{*} \mathrm{P}<0.05$ and ${ }^{\# \#} \mathrm{P}<0.01$ vs. LPS group. TA, tannic acid; LPS, lipopolysaccharide; Cont, control; FITC, fluorescein isothiocyanate; PI, propidium iodide.

A

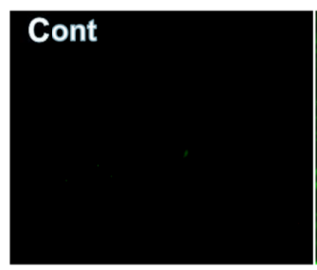

B

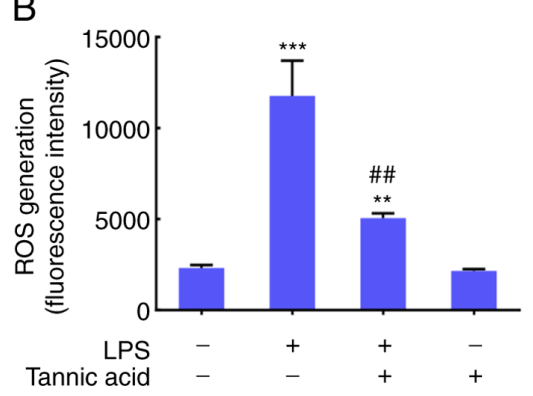

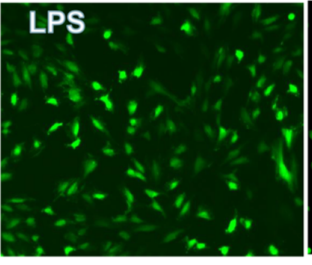

C

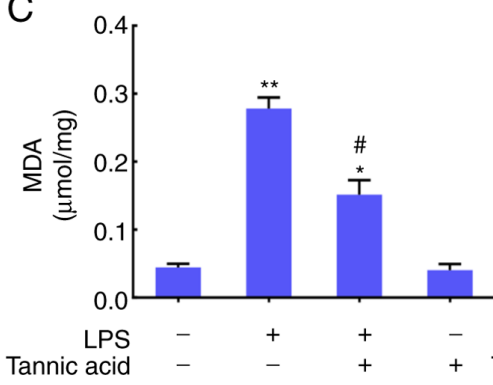

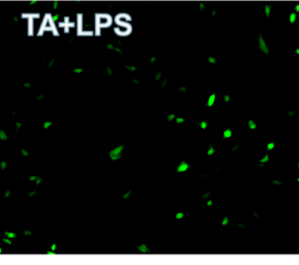

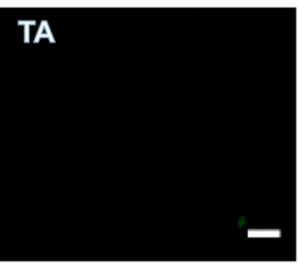

D

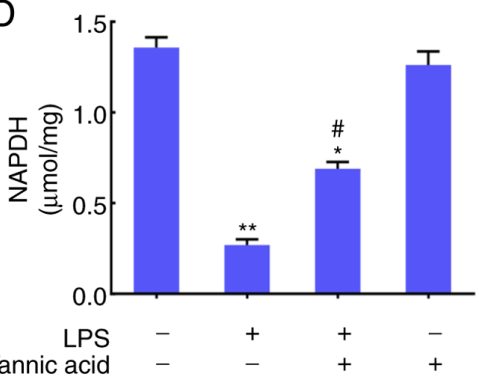

Figure 3. TA attenuates ROS production in LPS-induced H9C2 cells. (A) Laser confocal microscopy measurement of cellular ROS production by H9C2 cells treated with LPS, TA and TA + LPS (scale bar, $100 \mu \mathrm{m}$ ). (B) Semi-quantitative analysis of the mean fluorescence intensity following treatment with LPS, TA and TA + LPS. (C) Levels of MDA following treatment with LPS, TA and TA + LPS. (D) Levels of NAPDH following treatment with LPS, TA and TA + LPS. Data are presented as the mean \pm standard error of the mean $(\mathrm{n}=4) .{ }^{*} \mathrm{P}<0.05,{ }^{* *} \mathrm{P}<0.01$ and ${ }^{* * *} \mathrm{P}<0.001$ vs. Cont group; ${ }^{\#} \mathrm{P}<0.05$ and ${ }^{\# \#} \mathrm{P}<0.01$ vs. LPS group. ROS, reactive oxygen species; TA, tannic acid; LPS, lipopolysaccharide; Cont, control; MDA, malondialdehyde; NADPH, nicotinamide adenine dinucleotide phosphate.

The contents of MDA and NADPH in cells indicate oxidative damage and antioxidant capacity (35). The results of the present study demonstrated that LPS significantly increased the content of MDA in cells compared with that in the control group. The levels of MDA in the TA pretreatment group were significantly lower than those in the LPS treatment group (Fig. 3C). In addition, LPS treatment decreased the content of NADPH compared with that in the control group, whereas TA treatment significantly improved the levels of NADPH compared with those in the LPS treatment group (Fig. 3D). These results suggested that TA was capable of reducing intracellular ROS accumulation following LPS stimulation. The ability of TA to inhibit intracellular ROS production may contribute to its efficacy at protecting H9C2 cells against LPS-induced apoptosis.

TA alleviates LPS-induced ERS in H9C2 cells. To determine the effect of TA on ERS in H9C2 cells induced by LPS, the 
A

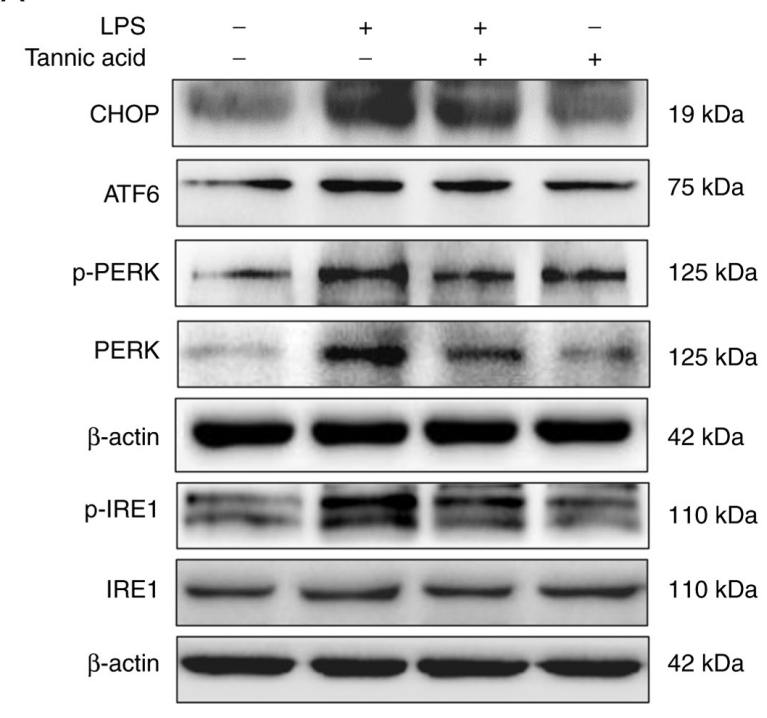

B
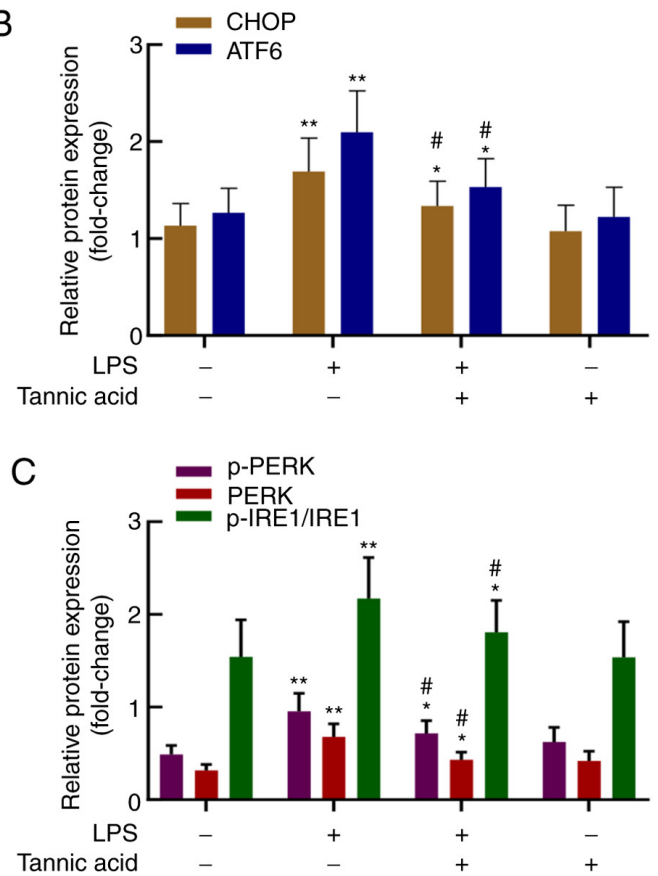

Figure 4. TA alleviates LPS-induced endoplasmic reticulum stress in H9C2 cells. (A) Protein expression levels of CHOP, ATF6, p-PERK, PERK, p-IRE1, IRE1 and $\beta$-actin in H9C2 cells treated with LPS, TA and TA + LPS, as determined by western blot analysis. Semi-quantification of the protein expression levels of (B) CHOP and ATF6, and (C) p-PERK, PERK and p-IRE1/IRE1 in the LPS, TA and TA + LPS groups. Data are presented as the mean \pm SEM ( $\mathrm{n}=3$ ). ${ }^{*} \mathrm{P}<0.05$ and ${ }^{* *} \mathrm{P}<0.01$ vs. control group; ${ }^{\#} \mathrm{P}<0.05$ vs. LPS group. TA, tannic acid; LPS, lipopolysaccharide; $\mathrm{CHOP}, \mathrm{C} / \mathrm{EBP}$-homologous protein; ATF6, activating transcription factor 6; p, phosphorylated; PERK, protein kinase-like endoplasmic reticulum kinase; IRE1, inositol-requiring enzyme 1.

expression levels of ERS associated proteins were examined. As presented in Fig. 4A-C, the expression levels of ERS associated proapoptotic proteins, CHOP, ATF6, p-PERK, PERK and p-IRE1/IRE1, were significantly increased following exposure to LPS compared with those in the control group. Moreover, both phosphorylated and total PERK levels increased following treatment, indicating that changes in phosphorylation of PERK may serve an important role in the PERK signaling pathway. By contrast, the expression levels of ERS associated proteins were markedly downregulated in the TA + LPS group compared with those in the group treated with LPS only. This result suggested that pretreatment with TA significantly downregulated the expression of ERS associated proteins, which alleviated LPS-induced ERS. Based on this finding, it may be hypothesized that the ERS associated proapoptotic proteins CHOP, ATF6, PERK and IRE1 could serve underlying roles in alleviating LPS-induced H9C2 cell apoptosis by TA.

TA attenuates LPS-induced apoptosis by suppressing ROS-mediated ERS in H9C2 cells. The present study further examined the protective effects of TA on H9C2 cells and explored the relationship between ROS and ERS-associated apoptosis in LPS-induced H9C2 cells. To determine whether LPS induced ROS-modulated ERS in H9C2 cells, the ROS scavenger, NAC, was used to evaluate the relationship between ROS, ERS and apoptosis. H9C2 cells were pretreated with $1 \mathrm{mM}$ NAC or $10 \mu \mathrm{M}$ TA, and then treated with $15 \mu \mathrm{g} / \mathrm{ml}$ LPS. The protein expression levels of ERS associated proteins (CHOP, ATF6, p-PERK, PERK, p-IRE1 and IRE1) and apoptosis-associated proteins ( $\mathrm{p}-\mathrm{JNK}$, JNK, cleaved caspase-3, Bax/Bcl-2 and cleaved caspase-9) were detected by western blotting (Figs. 5A-C and 6A-C). In addition, the mRNA expression levels of ER stress associated genes [Chop, Atf6, Perk, Ire1 and spliced X box-binding protein 1) and apoptosis-associated genes (Bax, caspase-3, caspase-12 and cytochrome $c$ (Cyt c)] were detected (Figs. 5D-H and 6D-G). LPS caused a significant increase in the expression of ERS associated proteins and apoptosis-associated proteins; however, these protein expression levels were markedly decreased following TA or NAC pretreatment (Figs. 5 and 6). Moreover, TA in the presence of ROS inhibitor NAC had no further effect on expression of ERS associated proteins and apoptosis-associated proteins compared with TA alone. The levels of all markers detected in the NAC-only group were similar to those observed in the control group. The present results indicated that ERS activation and apoptosis activation were inhibited by TA in a ROS-dependent manner, but not in the presence of NAC. ERS is considered one of the mechanisms contributing to ROS-mediated cell apoptosis (18). The present results also demonstrated that LPS-induced ROS modulated ERS in H9C2 cells (Fig. 5), suggesting that the ROS-mediated ERS pathway may be one of the important mechanistic pathways modulating apoptosis in LPS-induced H9C2 cells. Taken together, TA may prevent LPS-induced ROS-mediated ERS, which may be responsible for the TA-induced decrease in $\mathrm{H} 9 \mathrm{C} 2$ cell apoptosis.

\section{Discussion}

The major findings of the present study were as follows: i) The use of appropriate TA concentrations promoted an increase in the viability of LPS-induced H9C2 cells; ii) TA attenuated ROS, ERS and apoptosis in LPS-induced H9C2 cells; 
A

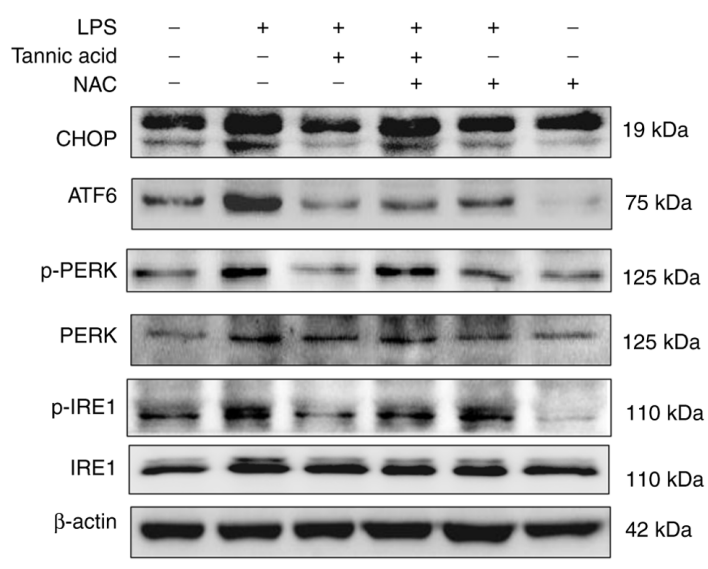

B

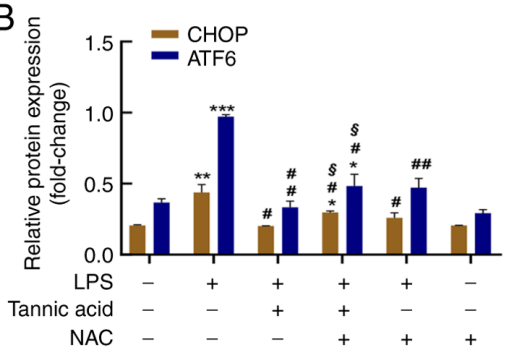

C

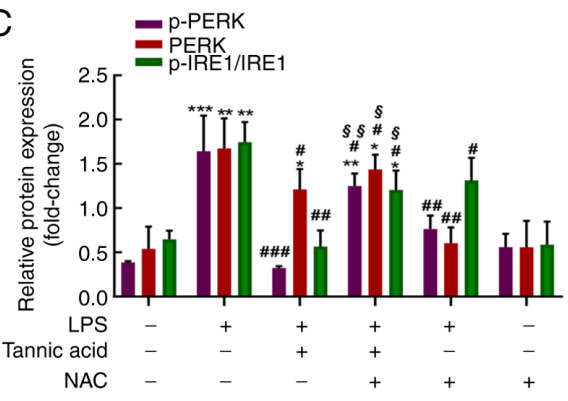

F

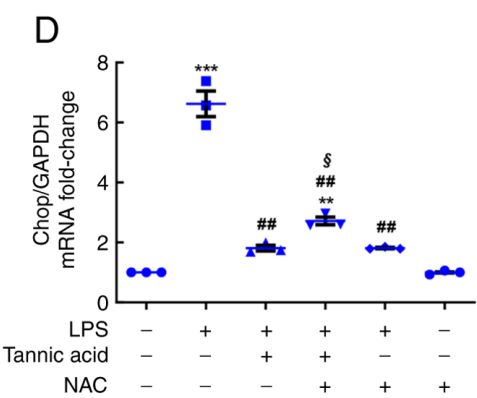

E

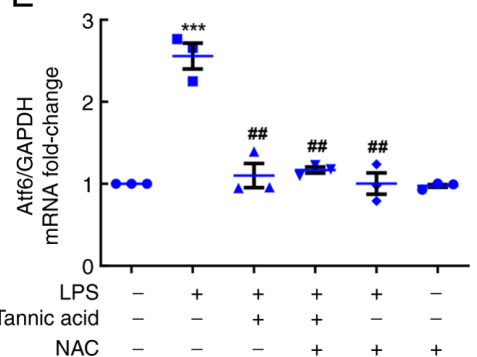

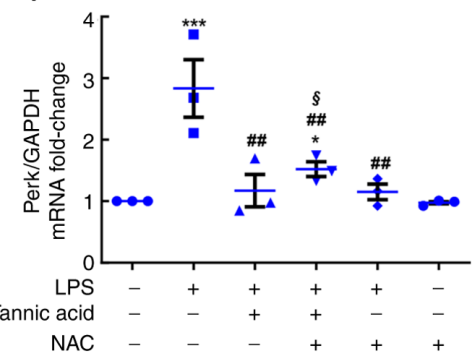

G

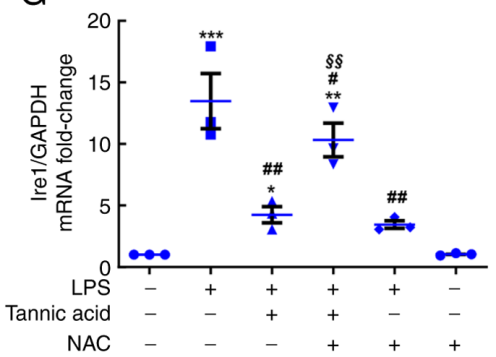

H

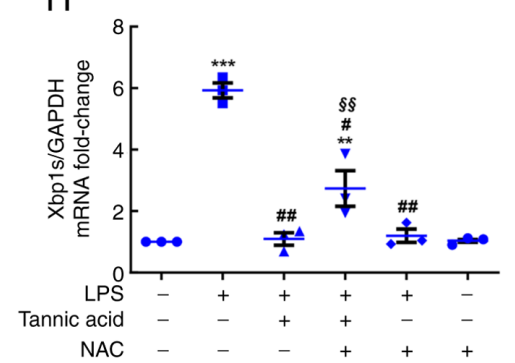

Figure 5. TA attenuates LPS-induced ER stress via suppressing ROS in $\mathrm{H} 9 \mathrm{C} 2$ cells. (A) Whole cell lysates were prepared following stimulation with LPS, NAC and TA. The protein expression levels of CHOP, ATF6, p-PERK, PERK, p-IRE1, IRE1 were detected in H9C2 cells treated with LPS, NAC + LPS, TA + LPS and TA + NAC + LPS by western blot analysis. Semi-quantification of the protein expression levels of (B) CHOP and ATF6, and (C) p-PERK, PERK and p-IRE1/IRE1 in H9C2 cells. The mRNA expression levels of (D) Chop, (E) Atf6, (F) Perk, (G) Ire1 and (H) Xbp1s in H9C2 cells normalized to Gapdh. Data are presented as the mean \pm SEM ( $=3$ ). ${ }^{*} \mathrm{P}<0.05,{ }^{* *} \mathrm{P}<0.01$ and ${ }^{* * * *} \mathrm{P}<0.001$ vs. control group; ${ }^{\#} \mathrm{P}<0.05,{ }^{\# \#} \mathrm{P}<0.01$ and ${ }^{\# \# \#} \mathrm{P}<0.001$ vs. LPS group; ${ }^{\circledR} \mathrm{P}<0.05$ and ${ }^{\$ \$} \mathrm{P}<0.01$ vs. TA + LPS. ER, endoplasmic reticulum; TA, tannic acid; LPS, lipopolysaccharide; NAC, N-acetylcysteine; CHOP/Chop, C/EBP-homologous protein; ATF6/Atf6, activating transcription factor 6; p, phosphorylated; PERK/Perk, protein kinase-like endoplasmic reticulum kinase; IRE1/Ire1, inositol-requiring enzyme 1; Xbp1s, spliced X box-binding protein 1.

iii) suppression of ROS-mediated ERS-related apoptosis in LPS-induced H9C2 cells was strongly involved in the protective effects of TA. Collectively, to the best of our knowledge, the present study was the first to demonstrate that TA protected against LPS-induced H9C2 cell apoptosis. Additionally, it was revealed that TA reduced the overproduction of ROS and the levels of ERS.

Sepsis is a serious disease associated with an extremely high mortality rate, similar to that of acute myocardial infarction $(36,37)$. SIMD has been defined as a sepsis-associated acute syndrome of cardiac dysfunction. As there is still no effective treatment strategy for SIMD, there is an urgent need to explore effective remedies and innovative treatment options to combat SIMD. LPS is the major component of the Gram-negative bacterial outer membrane and is considered the principal cause of multiorgan failure in sepsis, including myocardial depression $(38,39)$. LPS-induced H9C2 cells are often used in the study of septic cardiomyopathy. Several mechanisms have been proposed to explain the pathophysiology of SIMD, including the excessive generation of inflammatory cytokines (40), ROS (41), cell death (necrosis and apoptosis) (42), impairment of nitric oxide (43), overactivation of ERS (24). and transcriptional and compromised metabolic changes (44). Therefore, 

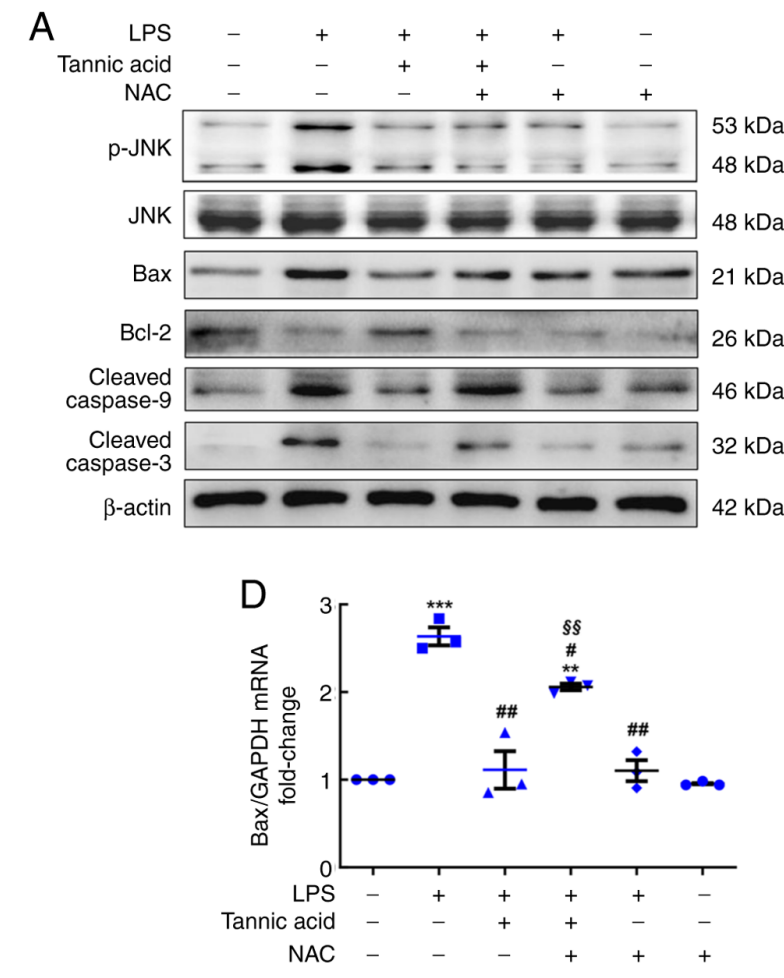
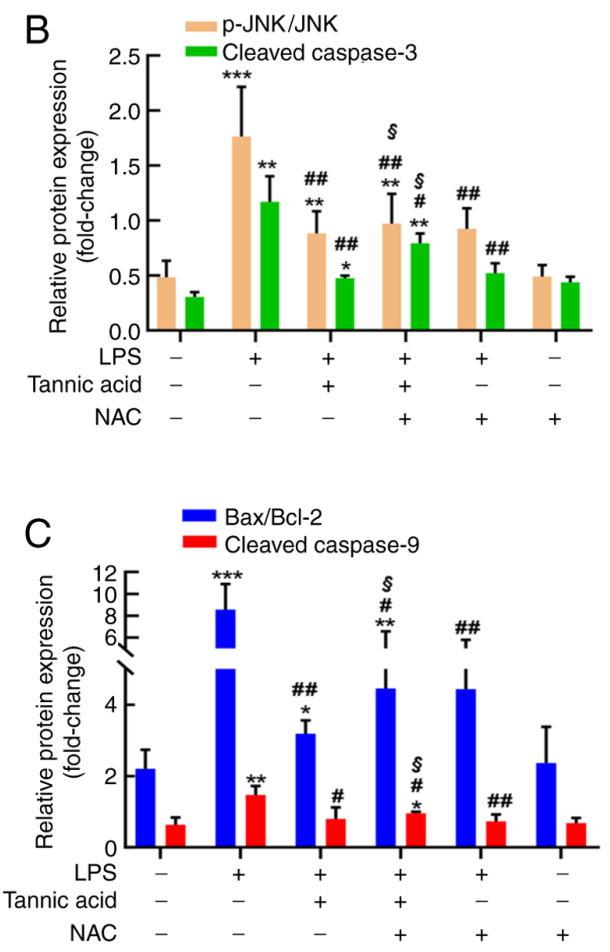
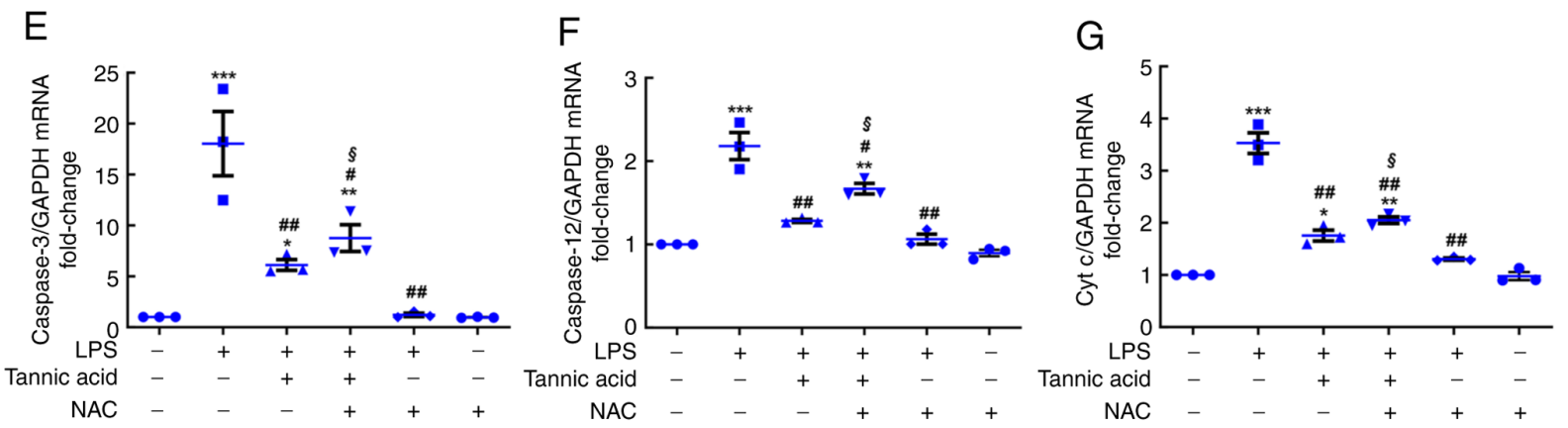

Figure 6. TA attenuates LPS-induced apoptosis via suppressing ROS-mediated endoplasmic reticulum stress in H9C2 cells. (A) Whole cell lysates were prepared following stimulation with LPS, NAC and TA. The protein expression levels of apoptosis-associated proteins (p-JNK, JNK, Bax, cleaved caspase-9 and cleaved caspase-3) and an anti-apoptotic protein (Bcl-2) were detected in H9C2 cells treated with LPS, NAC + LPS, TA + LPS and TA + NAC + LPS by western blot analysis. Semi-quantification of the protein expression levels of (B) p-JNK/JNK and cleaved caspase-3, and (C) Bax/Bcl-2 and cleaved caspase-9 in $\mathrm{H} 9 \mathrm{C} 2$ cells. The mRNA expression levels of (D) Bax, (E) caspase-3, (F) caspase-12 and (G) Cyt c in H9C2 cells normalized to Gapdh. Data are presented as the mean \pm standard error of the mean $(\mathrm{n}=3)$. ${ }^{*} \mathrm{P}<0.05,{ }^{* *} \mathrm{P}<0.01$ and ${ }^{* * *} \mathrm{P}<0.001$ vs. control; ${ }^{\#} \mathrm{P}<0.05$ and ${ }^{\# / \#} \mathrm{P}<0.01$ vs. LPS group; ${ }^{\circledR} \mathrm{P}<0.05$ and ${ }^{\circledR \S} \mathrm{P}<0.01$ vs. TA + LPS. TA, tannic acid; LPS, lipopolysaccharide; NAC, N-acetylcysteine; p, phosphorylated; JNK, c-Jun N-terminal kinase; Cyt c, cytochrome $c$.

anti-inflammatory agents, anti-apoptotic agents and antioxidants could be promising drugs to ameliorate SIMD.

TA is a natural polyphenol, which has been used to improve human health (45). TA has been reported to alleviate acute lung injury (46), cardiac hypertrophy (47), acute doxorubicin-induced cardiotoxicity (48) and isoproterenol-induced myocardial injury (30). However, to the best of our knowledge, there are no reports on the effects of TA on LPS-induced cardiomyocyte injury. The present study was performed to evaluate the possible mechanisms of action underlying TA-mediated prevention of $\mathrm{H} 9 \mathrm{C} 2$ cardiomyocyte injury. The present study demonstrated that administration of TA at high doses ( 40 and $50 \mu \mathrm{M})$ induced cell injury, whereas doses of $\mathrm{TA} \leq 20 \mu \mathrm{M}$ were nontoxic to $\mathrm{H} 9 \mathrm{C} 2$ cells. When investigating the protective effect of TA against LPS-induced cell injury using the CCK-8 assay, the capacity of TA to protect H9C2 cells from LPS-induced cell injury was observed in a dose-dependent manner, though cell viability was slightly decreased in response to $20 \mu \mathrm{M}$ TA compared with $15 \mu \mathrm{M}$ TA.

ROS are well-known to trigger apoptosis through activation of essential stress signaling molecules, including JNK $(49,50)$. Moreover, the mitochondrion is a source of ROS. Mitochondrial dysfunction has been reported to be associated with Cyt $\mathrm{c}$ release and the loss of mitochondrial membrane potential, which can ultimately result in increased apoptosis (51). ROS are key initiation factors for oxidative stress; excessive ROS in the body can induce oxidative stress $(52,53)$. Numerous studies have shown that oxidative stress has an important role in the pathogenesis of sepsis $(9,54)$. The present study revealed that ROS levels were increased in LPS-induced $\mathrm{H} 9 \mathrm{C} 2$ cells; however, TA was able to significantly inhibit ROS levels and apoptosis in LPS-induced H9C2 cells. These findings confirmed the potential antioxidant and anti-apoptotic function of TA in LPS-induced H9C2 cells. 
In addition to their dangerous and rapid reactivity against cellular components, ROS have been recognized as potential signaling molecules for initiating various cellular events (55). The production of ROS is very complex. Previous studies have suggested that ERS may be induced by increased ROS production within the myocardium $(56,57)$, and the overexpression of ROS may further result in the dysregulation of the ER, complex UPR signaling pathway and cell apoptosis (18). In accordance with these findings, the present study determined the close relationship between ROS and ERS. The results revealed that ROS mediated ERS-related apoptosis in LPS-induced H9C2 cells.

ERS is known to be mediated by threeknown transmembrane sensor proteins, namely IRE1, ATF6 and PERK (58). ERS-related CHOP, caspase-12 and/or JNK-dependent apoptotic signaling pathways can be activated by a severe stimulus, which in turn affects the expression of Bax/Bcl-2 and the activation of caspase-3 $(22,59)$. Increased CHOP expression has been reported to upregulate the cytoplasmic pro-apoptotic protein Bax and induce the release of $\mathrm{Cyt} \mathrm{c}$ from the mitochondria, leading to the activation of caspase- 3 and caspase-9, and the induction of cell apoptosis (60). The present study observed that ERS was triggered by LPS administration, eventually resulting in $\mathrm{H} 9 \mathrm{C} 2$ cell injury. Additionally, it was demonstrated that TA was able to significantly inhibit ERS in the LPS-induced H9C2 cells. To the best of our knowledge, no research has been conducted on the effect of TA on the link between ROS and ERS-related apoptosis in LPS-induced H9C2 cells. Therefore, further investigations are required to determine whether ERS serves an important role in ROS-scavenging by TA to reduce H9C 2 cardiomyocyte injury. NAC, a well-known ROS scavenger, was utilized as a positive control in the present study to treat H9C2 cells; LPS-induced H9C2 cells were preincubated with TA and/or NAC. The results demonstrated that inhibition of ROS significantly suppressed the expression of ERS-associated functional proteins induced by LPS; however, the expression of ERS associated proteins could not be further suppressed by TA in the presence of NAC in LPS-induced H9C2 cells compared with TA-alone. It was also suggested that the inhibition of ROS significantly suppressed ERS-associated apoptotic proteins, including JNK, Bax, Cyt c, caspase-3, caspase-12 and caspase-9. Moreover, $\mathrm{NAC}+\mathrm{TA}$ had no further effect on expression compared with TA-alone. These results demonstrated that ERS activation and apoptosis activation were inhibited by TA partly in a ROS-dependent manner.

The present study suggested that TA suppressed ROS-mediated ERS-related apoptosis in LPS-induced H9C2 cells. Although the present study indicated that TA attenuated ROS, ERS and apoptosis in LPS-induced H9C2 cells, there are discrepancies compared with other papers on different cell types; for example, in a previous study on prostate cancer cells, it was revealed that TA induced apoptosis, particularly by mediating ERS (61). TA also induces apoptosis by mediating ROS (62). The present study did not assess other cell models and therefore it is unclear whether TA can protect numerous cell types from apoptosis. In addition, in the LPS-induced H9C2 cell injury model, the present study only assessed the effect of TA on apoptosis, and did not study the effect of TA on the inflammatory response. Inflammatory factors need to be further studied in follow-up studies. Furthermore, although the present study suggested that the ROS-mediated ERS-associated apoptosis exerted important functions in the LPS-induced H9C2 cell injury model, there may be some differences in an in vivo context. H9C2 cells were originally derived from embryonic cardiac tissue; however, in vivo cardiac myocytes have more complex functions. To better understand the mechanisms involved in cardiac injury, additional studies are required in the future to evaluate these findings and to identify more specific mechanisms in vivo.

In conclusion, the present study demonstrated that TA may protect LPS-induced H9C2 cells against damage via the suppression of ROS-mediated ERS-associated apoptosis, providing a comprehensive understanding of the mechanisms underlying the cardioprotective role of TA. Based on these findings, TA may be targeted as an efficient therapeutic drug for the treatment of SIMD to improve heart function.

\section{Acknowledgements}

Not applicable.

\section{Funding}

This study was funded by the National Natural Science Foundation of China (grant no. 91439126).

\section{Availability of data and materials}

The datasets used and/or analyzed during the current study are available from the corresponding author on reasonable request.

\section{Authors' contributions}

YPY, YHL and XL conceived the study. YPY and XL designed the experiments. YPY, JQZ, HBG, JJL, XLL and XLN performed the experiments, and acquired and analyzed the data. YPY and XL wrote the manuscript. All authors confirm the authenticity of all the raw data. All authors read and approved the final manuscript.

\section{Ethics approval and consent to participate}

Not applicable.

\section{Patient consent for publication}

Not applicable.

\section{Competing interests}

The authors declare that they have no competing interests.

\section{References}

1. Rocheteau P, Chatre L, Briand D, Mebarki M, Jouvion G, Bardon J, Crochemore C, Serrani P, Lecci PP, Latil M, et al: Sepsis induces long-term metabolic and mitochondrial muscle stem cell dysfunction amenable by mesenchymal stem cell therapy. Nat Commun 6: 10145, 2015. 
2. Paoli CJ, Reynolds MA, Sinha M, Gitlin M and Crouser E: Epidemiology and costs of sepsis in the United States-An analysis based on timing of diagnosis and severity level. Crit Care Med 46: 1889-1897, 2018

3. Huang M, Cai S and Su J: The Pathogenesis of sepsis and potential therapeutic targets. Int J Mol Sci 20: 20, 2019.

4. Gaieski DF, Edwards JM,Kallan MJ and Carr BG: Benchmarking the incidence and mortality of severe sepsis in the United States. Crit Care Med 41: 1167-1174, 2013.

5. Zhang T, Yan T, Du J, Wang S and Yang H: Apigenin attenuates heart injury in lipopolysaccharide-induced endotoxemic model by suppressing sphingosine kinase $1 /$ sphingosine 1-phosphate signaling pathway. Chem Biol Interact 233: 46-55, 2015.

6. Lambden S, Creagh-Brown BC, Hunt J, Summers C and Forni LG: Definitions and pathophysiology of vasoplegic shock. Crit Care 22: 174, 2018.

7. Martin L, Derwall M, Al Zoubi S, Zechendorf E, Reuter DA, Thiemermann C and Schuerholz T: The Septic Heart: Current understanding of molecular mechanisms and clinical implications. Chest 155: 427-437, 2019.

8. Lv X and Wang H: Pathophysiology of sepsis-induced myocardial dysfunction. Mil Med Res 3: 30, 2016.

9. Liu YC, Yu MM, Shou ST and Chai YF: Sepsis-induced cardiomyopathy: Mechanisms and treatments. Front Immunol 8: $1021,2017$.

10. Drosatos K, Lymperopoulos A, Kennel PJ, Pollak N, Schulze PC and Goldberg IJ: Pathophysiology of sepsis-related cardiac dysfunction: Driven by inflammation, energy mismanagement, or both? Curr Heart Fail Rep 12: 130-140, 2015.

11. Bai T, Hu X, Zheng Y, Wang S, Kong J and Cai L: Resveratrol protects against lipopolysaccharide-induced cardiac dysfunction by enhancing SERCA2a activity through promoting the phospholamban oligomerization. Am J Physiol Heart Circ Physiol 311: H1051-H1062, 2016.

12. Kakihana Y, Ito T, Nakahara M, Yamaguchi $\mathrm{K}$ and Yasuda T: Sepsis-induced myocardial dysfunction: Pathophysiology and management. J Intensive Care 4: 22, 2016.

13. Tan S, Long Z, Hou X, Lin Y, Xu J, You X, Wang T and Zhang Y: H2 Protects Against lipopolysaccharide-induced cardiac dysfunction via blocking TLR4-mediated cytokines expression. Front Pharmacol 10: 865, 2019.

14. Turdi S, Han X, Huff AF, Roe ND, Hu N, Gao F and Ren J: Cardiac-specific overexpression of catalase attenuates lipopolysaccharide-induced myocardial contractile dysfunction: Role of autophagy. Free Radic Biol Med 53: 1327-1338, 2012.

15. Jiang W, Luo F, Lu Q, Liu J, Li P, Wang X, Fu Y, Hao K, Yan T and Ding X: The protective effect of Trillin LPS-induced acute lung injury by the regulations of inflammation and oxidative state. Chem Biol Interact 243: 127-134, 2016.

16. Qi XF, Zheng L, Lee KJ, Kim DH, Kim CS, Cai DQ, Wu Z, Qin JW, Yu YH and Kim SK: HMG-CoA reductase inhibitors induce apoptosis of lymphoma cells by promoting ROS generation and regulating Akt, Erk and p38 signals via suppression of mevalonate pathway. Cell Death Dis 4: e518, 2013.

17. Ding W, Yang L, Zhang M and Gu Y: Reactive oxygen species-mediated endoplasmic reticulum stress contributes to aldosterone-induced apoptosis in tubular epithelial cells Biochem Biophys Res Commun 418: 451-456, 2012.

18. Liu ZW, Zhu HT, Chen KL, Dong X, Wei J, Qiu C and Xue JH: Protein kinase RNA-like endoplasmic reticulum kinase (PERK) signaling pathway plays a major role in reactive oxygen species (ROS)-mediated endoplasmic reticulum stress-induced apoptosis in diabetic cardiomyopathy. Cardiovasc Diabetol 12: $158,2013$.

19. Li D, Cong Z, Yang C and Zhu X: Inhibition of LPS-induced Nox 2 activation by VAS2870 protects alveolar epithelial cells through eliminating ROS and restoring tight junctions. Biochem Biophys Res Commun 524: 575-581,2020.

20. Li A, Song NJ, Riesenberg BP and Li Z: The emerging roles of endoplasmic reticulum stress in balancing immunity and tolerance in health and diseases: Mechanisms and opportunities. Front Immunol 10: 3154, 2020

21. Oyadomari S, Yun C, Fisher EA, Kreglinger N, Kreibich G, Oyadomari M, Harding HP, Goodman AG, Harant $H$, Garrison JL, et al: Cotranslocational degradation protects the stressed endoplasmic reticulum from protein overload. Cell 126: 727-739, 2006.

22. Wang M and Kaufman RJ: Protein misfolding in the endoplasmic reticulum as a conduit to human disease. Nature 529: 326-335, 2016.
23. Liu L, Wu H, Zang J, Yang G, Zhu Y, Wu Y, Chen X, Lan D and $\mathrm{Li}$ T: 4-Phenylbutyric acid reveals good beneficial effects on vital organ function via anti-endoplasmic reticulum stress in septic rats. Crit Care Med 44: e689-e701, 2016.

24. Khan MM, Yang WL and Wang P: Endoplasmic reticulum stress in sepsis. Shock 44: 294-304, 2015.

25. Salminen JP and Karonen M: Chemical ecology of tannins and other phenolics: We need a change in approach. Funct Ecol 25: 325-338, 2011

26. Darvin P, Joung YH, Kang DY, Sp N, Byun HJ, Hwang TS, Sasidharakurup $\mathrm{H}$, Lee $\mathrm{CH}$, Cho KH, Park KD, et al: Tannic acid inhibits EGFR/STAT1/3 and enhances p38/STAT1 signalling ax is in breast cancer cells. J Cell Mol Med 21: 720-734, 2017.

27. Pattarayan D, Sivanantham A, Krishnaswami V, Loganathan L, Palanichamy R, Natesan S, Muthusamy K and Rajasekaran S: Tannic acid attenuates TGF- $\beta 1$-induced epithelial-to-mesenchymal transition by effectively intervening TGF- $\beta$ signaling in lung epithelial cells. J Cell Physiol 233: 2513-2525, 2018.

28. Pattarayan D, Sivanantham A, Bethunaickan R, Palanichamy R and Rajasekaran S: Tannic acid modulates fibroblast proliferation and differentiation in response to pro-fibrotic stimuli. J Cell Biochem 119: 6732-6742, 2018.

29. Sivanantham A, Pattarayan D, Bethunaickan R, Kar A, Mahapatra SK, Thimmulappa RK, Palanichamy R and Rajasekaran S: Tannic acid protects against experimental acute lung injury through downregulation of TLR4 and MAPK. J Cell Physiol 234: 6463-6476, 2019.

30. Hu X, Wang H, Lv X, Chu L, Liu Z, Wei X, Chen Q, Zhu L and Cui W: Cardioprotective effects of tannic acid on isoproterenol-induced myocardial injury in rats: Further insight into 'French Paradox'. Phytother Res 29: 1295-1303, 2015.

31. Zheng Y, Li S, Hu R, Cheng F and Zhang L: GFI-1 protects against lipopolysaccharide-induced inflammatory responses and apoptosis by inhibition of the NF- $\kappa \mathrm{B} / \mathrm{TNF}-\alpha$ pathway in $\mathrm{H} 9 \mathrm{c} 2$ Cells. Inflammation 43: 74-84, 2020.

32. Shan P, Pu J, Yuan A, Shen L, Shen L, Chai D and He B: RXR agonists inhibit oxidative stress-induced apoptosis in $\mathrm{H} 9 \mathrm{c} 2$ rat ventricular cells. Biochem Biophys Res Commun 375: 628-633, 2008.

33. Lei Y, Yang Y, Zhao J, Gao H, Chen R, Bai B, Kang X, He Y, Ding L, Wei T, et al: P-AKT2/SPK1 (P-SPK1) and P-MEK/P-ERK cell signaling pathways are involved in LPS-induced macrophage migration. Am J Transl Res 11: 2725-2741, 2019.

34. Zhao J, Lei Y, Yang Y, Gao H, Gai Z and Li X: Metoprolol alleviates arginine vasopressin-induced cardiomyocyte hypertrophy by upregulating the AKT1-SERCA2 cascade in H9C2 cells. Cell Biosci 10: 72, 2020.

35. Song Q, Liu L, Yu J, Zhang J, Xu M, Sun L, Luo H, Feng Z and Meng G: Dihydromyricetin attenuated Ang II induced cardiac fibroblasts proliferation related to inhibitory of oxidative stress. Eur J Pharmacol 807: 159-167, 2017.

36. Kotfis K, Wittebole X, Jaschinski U, Solé-Violán J, Kashyap R, Leone M, Nanchal R, Fontes LE, Sakr Y and Vincent JL; ICON Investigators: A worldwide perspective of sepsis epidemiology and survival according to age: Observational data from the ICON audit. J Crit Care 51: 122-132, 2019.

37. Keeley A, Hine P and Nsutebu E: The recognition and management of sepsis and septic shock: A guide for non-intensivists. Postgrad Med J 93: 626-634, 2017.

38. Opal SM, Scannon PJ, Vincent JL, White M, Carroll SF, Palardy JE, Parejo NA, Pribble JP and Lemke JH: Relationship between plasma levels of lipopolysaccharide (LPS) and LPS-binding protein in patients with severe sepsis and septic shock. J Infect Dis 180: 1584-1589, 1999.

39. Li Y, Ge S, Peng Y and Chen X: Inflammation and cardiac dysfunction during sepsis, muscular dystrophy, and myocarditis. Burns Trauma 1: 109-121, 2013

40. Hu D, Yang X, Xiang Y, Li H, Yan H, Zhou J, Caudle Y, Zhang $X$ and Yin D: Inhibition of Toll-like receptor 9 attenuates sepsis-induced mortality through suppressing excessive inflammatory response. Cell Immunol 295: 92-98, 2015.

41. Lowes DA, Webster NR, Murphy MP and Galley HF: Antioxidants that protect mitochondria reduce interleukin-6 and oxidative stress, improve mitochondrial function, and reduce biochemical markers of organ dysfunction in a rat model of acute sepsis. Br J Anaesth 110: 472-480, 2013

42. Zhang Y, Xu X, Ceylan-Isik AF, Dong M, Pei Z, Li Y and Ren J: Ablation of Akt2 protects against lipopolysaccharide-induced cardiac dysfunction: Role of Akt ubiquitination E3 ligase TRAF6. J Mol Cell Cardiol 74: 76-87, 2014. 
43. Luiking YC, Poeze M and Deutz NE: Arginine infusion in patients with septic shock increases nitric oxide production without haemodynamic instability. Clinical science (London, England: 1979) 128: 57 67, 2015.

44. Wilson J, Higgins D, Hutting H, Serkova N, Baird C, Khailova L, Queensland K, Vu Tran Z, Weitzel L and Wischmeyer PE: Early propranolol treatment induces lung heme-oxygenase-1, attenuates metabolic dysfunction, and improves survival following experimental sepsis. Crit Care 17: R195, 2013.

45. Nie F, Liang Y, Jiang B, Li X, Xun H, He W, Lau HT and Ma X: Apoptotic effect of tannic acid on fatty acid synthase over-expressed human breast cancer cells. Tumour Biol 37: 2137-2143, 2016.

46. Zhang T, Zhang R, Dang M, Qiu S, Gu H, He P and Guo G: Ameliorative effects of tannic acid on lipopolysaccharide induced sepsis and acute lung injury in mice. Pharmacogn Mag 15: 15, 2019.

47. Chu L, Li P, Song T, Han X, Zhang X, Song Q, Liu T, Zhang Y and Zhang J: Protective effects of tannic acid on pressure overload-induced cardiac hypertrophy and underlying mechanisms in rats. J Pharm Pharmacol 69: 1191-1207, 2017.

48. Zhang J, Cui L, Han X, Zhang Y, Zhang X, Chu X, Zhang F, Zhang Y and Chu L: Protective effects of tannic acid on acute doxorubicin-induced cardiotoxicity: Involvement of suppression in oxidative stress, inflammation, and apoptosis. Biomed Pharmacother 93: 1253-1260, 2017.

49. Fiers W, Beyaert R, Declercq W and Vandenabeele P: More than one way to die: Apoptosis, necrosis and reactive oxygen damage. Oncogene 18: 7719-7730, 1999.

50. Sakon S, Xue X, Takekawa M, Sasazuki T, Okazaki T, Kojima Y, Piao JH, Yagita H, Okumura K, Doi T, et al: NF-kappaB inhibits TNF-induced accumulation of ROS that mediate prolonged MAPK activation and necrotic cell death. EMBO J 22 : 3898-3909, 2003.

51. Quoilin C, Mouithys-Mickalad A, Lécart S, Fontaine-Aupart MP and Hoebeke M: Evidence of oxidative stress and mitochondrial respiratory chain dysfunction in an in vitro model of sepsis-induced kidney injury. Biochim Biophys Acta 1837: 1790-1800, 2014

52. Wible DJ and Bratton SB: Reciprocity in ROS and autophagic signaling. Curr Opin Toxicol 7: 28-36, 2018.
53. Bardaweel SK, Gul M, Alzweiri M, Ishaqat A, ALSalamat HA and Bashatwah RM: Reactive oxygen species: The dual role in physiological and pathological conditions of the human body. Eurasian J Med 50: 193-201, 2018.

54. L'Heureux M, Sternberg M, Brath L, Turlington J and Kashiouris MG: Sepsis-induced cardiomyopathy: A comprehensive review. Curr Cardiol Rep 22: 35, 2020.

55. Prauchner CA: Oxidative stress in sepsis: Pathophysiological implications justifying antioxidant co-therapy. Burns 43: 471-485, 2017.

56. Xu Y, Liu P, Xu S, Koroleva M, Zhang S, Si S and Jin ZG: Tannic acid as a plant-derived polyphenol exerts vasoprotection via enhancing KLF2 expression in endothelial cells. Sci Rep 7: 6686, 2017.

57. Li YH, Zhang WL, Zhou HY, Yu DW, Sun XN and Hu Q: Halofuginone protects against advanced glycation end products induced injury of $\mathrm{H} 9 \mathrm{C} 2$ cells via alleviating endoplasmic reticulum stress associated apoptosis and inducing autophagy. Mol Med Rep 20: 3131-3139, 2019.

58. Cheng YC, Chen CA and Chen HC: Endoplasmic reticulum stress-induced cell death in podocytes. Nephrology (Carlton) 22 (Suppl 4): 43-49, 2017.

59. Tabas I and Ron D: Integrating the mechanisms of apoptosis induced by endoplasmic reticulum stress. Nat Cell Biol 13: 184-190, 2011.

60. Yang J, Wu Q, Lv J and Nie H: 4-Phenyl butyric acid prevents glucocorticoid-induced osteoblast apoptosis by attenuating endoplasmic reticulum stress. J Bone Miner Metab 35: 366-374, 2017.

61. Nagesh PKB, Hatami E, Chowdhury P, Kashyap VK, Khan S, Hafeez BB, Chauhan SC, Jaggi M and Yallapu MM: Tannic acid induces endoplasmic reticulum stress-mediated apoptosis in prostate cancer. Cancers (Basel) 10: 10, 2018.

62. Nagesh PKB, Chowdhury P, Hatami E, Jain S, Dan N, Kashyap VK, Chauhan SC, Jaggi M and Yallapu MM: Tannic acid inhibits lipid metabolism and induce ROS in prostate cancer cells. Sci Rep 10: 980, 2020.

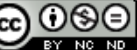

\footnotetext{
This work is licensed under a Creative Commons Attribution-NonCommercial-NoDerivatives 4.0 International (CC BY-NC-ND 4.0) License.
} 